Alelos del complejo mayor de histocompatibilidad BoLA clase II asociados a la resistencia y susceptibilidad a Boophilus microplus en ganado bovino, Junín - Perú

\title{
Alleles of major histocompatibility complex BoLA class II associated with resistance and susceptibility to Boophilus microplus in cattle, Junín, Peru
}

\author{
Custodio Villanueva M. ${ }^{1,{ }^{*}}$, López Bonilla C.F. ${ }^{2}$ y Arauco Villar F. ${ }^{1}$ \\ ${ }^{1}$ Facultad de Zootecnia de la Universidad Nacional del Centro del Perú \\ ${ }^{2}$ Instituto de Biotecnología de la Universidad Nacional Agraria La Molina
}

Recibido 07 junio 2011; aceptado 12 agosto 2011

\begin{abstract}
Resumen
El objetivo del presente estudio fue identificar mediante la amplificación de microsatélites, los alelos del Complejo Mayor de Histocompatibilidad (CMH) BoLA Clase II asociados a la resistencia y susceptibilidad a Boophilus microplus en ganado bovino, Junín -Perú. Se recolectaron muestras de sangre de 47 bovinos, así como, ejemplares de B. microplus durante los meses de marzo, abril y mayo del 2009, en horas de la mañana, del lado derecho de cada animal. La extracción del ADN genómico se realizó por el método de Phil Summers (1995) y la amplificación de los microsatélites DRB3.2, DRB31 y BM1815 fue por PCR en un secuenciador automático. Los datos fueron evaluados mediante el programa POPGEN 32. Se identificaron los alelos A, B y $\mathrm{C}$ relacionados con la resistencia y susceptibilidad a B. microplus en ganado bovino tanto en el locus BoLA DRB3.2 como en BoLA BM1815. Las frecuencias alélicas estimadas fueron: en el locus DRB3.2 la frecuencia del alelo A fue de 0.2742 , del alelo B fue de 0.5000 y del alelo C fue de 0.2258 ; en el locus DRB31 la frecuencia del alelo A fue de $1.0000 \mathrm{y}$, en el locus BM1815 la frecuencia del alelo A fue de 0.3295, del alelo B fue de 0.5909 y del alelo C fue de 0.0795. Se concluye que los alelos A, B y C de los loci DRB3.2 y BM1815 del Complejo Mayor de Histocompatibilidad BoLA Clase II están relacionados con la resistencia a B. microplus en ganado bovino y el alelo A del locus DRB31 está relacionado con la susceptibilidad.
\end{abstract}

Palabras clave: alelos, BoLA Clase II, resistencia, susceptibilidad, Boophilus microplus.

\begin{abstract}
The aim of this study was identified by amplification of microsatellite alleles of the Major Histocompatibility Complex BoLA Class II associated with resistance and susceptibility to Boophilus microplus in cattle, Junín, Peru. We collected blood sample of 47 cattle, as well as specimens of B. microplus during the months of march, april and may 2009 in the morning, the right side of each animal. Genomic DNA extraction was performed by the method of Phil Summers (1995) and amplification of microsatellites DRB3.2, DRB31 and BM1815 was by PCR in an automatic sequencer. Data were evaluated using the program POPG 32 . We identified alleles A, B and C related to resistance and susceptibility to B. microplus in cattle both in the BoLA locus BoLA DRB3.2 as BM1815. Allele frequencies were estimated: the DRB3.2 locus allele frequency was 0.2742 , allele B was 0.5000 and the $\mathrm{C}$ allele was 0.2258 , in the DRB31 locus allele frequency was 1.0000 and at the BM1815 locus allele frequency was 0.3295, allele B was 0.5909y the C allele was 0.0795. We conclude that the alleles A, B and C loci BM1815 DRB3.2 and Major Histocompatibility Complex Class II BoLA are associated with resistance to B. microplus in cattle and DRB31 locus allele is associated with susceptibility. Keywords: alleles, BoLA Class II, resistance, susceptibility, Boophilus microplus.
\end{abstract}

\section{Introducción}

En las regiones tropicales y subtropicales del mundo, los sistemas de producción ganadera han dejado de ser especializadas, para poder diversificar sus producciones, mestizando el ganado, a fin de mejorar los

\footnotetext{
* Autor para correspondencia

Email: macuvi2@yahoo.es (M. Custodio)
} 
ingresos económicos mediante cruces interraciales, para obtener ganado de doble propósito. Sin embargo, este tipo de ganado es afectado por diferentes agentes etiológicos de enfermedades, tales como: virus, bacterias, hongos y parásitos. De éstos últimos, la garrapata Boophilus microplus y las enfermedades transmitidas por ella son uno de los mayores problemas en salud veterinaria y salud pública en estas regiones, debido a los efectos patógenos que causa (Mendiola et al., 1997; Hernández et al., 2000; FAO, 2003; Álvarez et al., 2003). Las pérdidas principales que sufren los criadores de ganado bovino por la incidencia de este parásito son la muerte de los animales y la disminución de la producción de leche, carne y cuero (Jonsson et al., 2000; Acosta et al., 2004). La infestación es más abundante en los bovinos de razas europeas que en los bovinos de razas cebuínas (Villar, 2006).

El control de B. microplus basado en el uso continuo de pesticidas ha traído consigo la aparición de resistencia a acaricidas y presencia de residuos en los productos de origen animal (Benavides y Romero, 2001), constituyéndose ello, en desventaja para el ganadero de entrar a un mercado de exportación; ya que, uno de los requisitos internacionales para la comercialización de la carne, además de proceder de áreas libres de fiebre aftosa es que la carne bovina debe encontrarse libre de cualquier tipo de sustancias tóxicas para el organismo humano. No obstante las exigencias del mercado, el método de control de $B$. microplus con mejores resultados es la convergencia de la resistencia del hospedador aunado a la vacunación o baños estratégicos.

Durante los últimos años, se han desarrollado una serie de herramientas analíticas basadas en la aplicación de biotecnologías para el estudio directo del ADN. El análisis del BoLA ha demostrado sin lugar a dudas, la participación de genes en la expresión de características fisiológicas y patológicas (Teale et al., 1994). Inicialmente se exploró la distribución genética del BoLA con métodos serológicos, identificando la contribución de genes del BoLA en diversas enfermedades. Actualmente se definen sus alelos molecularmente, debido a que el polimorfismo también es extraordinario en animales domésticos y los métodos convencionales no son suficientes para su definición (Hess et al., 1999). A pesar de que la identificación de sus microsatélites es actualmente una herramienta muy útil para su análisis, aún es escasa la información sobre la identificación de microsatélites involucrados en conferir resistencia y susceptibilidad hacia $B$. microplus en ciertos tipos de bovinos explotados en zonas tropicales del Perú.

El objetivo del presente estudio fue identificar mediante la amplificación de microsatélites, los alelos del Complejo Mayor de Histocompatibilidad (CMH) BoLA Clase II asociados a la resistencia y susceptibilidad a Boophilus microplus en ganado bovino, Junín - Perú.

\section{Materiales y métodos}

Se emplearon 47 bovinos; de los cuales, 33 correspondieron a $B$. indicus y 13 a los híbridos de éstos con Bos taurus, procedentes de la Estación Experimental Agropecuaria de Satipo y uno correspondió a $B$. taurus, procedente de la Estación Experimental El Mantaro de la Universidad Nacional del Centro del Perú. La sangre fue colectada de la vena caudal del animal en tubos con EDTA y transportada en hielo seco al Laboratorio del Instituto de Biotecnología de la Universidad Nacional Agraria La Molina. El ADN se obtuvo mediante el método de Phil Summers (1995). Asimismo, para identificar a los animales resistentes y susceptibles se colectaron ejemplares de $B$. microplus durante los meses de marzo, 
abril y mayo del 2009, del lado derecho de cada animal, de las cuatro regiones corporales donde habitualmente se localizan las garrapatas: región tras del antebrazo y del codo por debajo del pecho, tras de la pierna, debajo de la base de la cola y nalga. Las garrapatas que se tomaron en cuenta fueron las que alcanzaron longitudes entre 4.5 y $8.0 \mathrm{~mm}$ por $5 \mathrm{~mm}$ de diámetro. La reacción en cadena de la polimerasa (PCR) se llevó a cabo en un termociclador Perkin Elmer 9700. Utilizándose en los programas de amplificación similares tiempos para la desnaturalización del ADN, alineamiento de iniciadores y elongación del ADN, diferentes temperaturas en la alineación de iniciadores; y variando el número de ciclos, habiéndose seleccionado los programas que generaba bandas más claras y definidas. La separación de los productos de amplificación procedentes de la PCR se llevó a cabo mediante electroforesis en geles de agarosa al 1.4\%. El tamaño de las bandas resultantes se estimó comparando las muestras con el marcador de peso molecular comercial.

Las imágenes se procesaron con el programa Adobe Photo Shop 7.0 y se convirtieron en datos binarios de cero (0) para la ausencia de la banda, (1) para la presencia y (9) para datos dudosos. Los resultados se guardaron en hojas de Microsoft Excel 2003 y fueron analizados mediante el programa de análisis de genética de poblaciones POPGEN 32 (Yeh et al., 1997). Este programa permite analizar la variabilidad genética dentro y entre las poblaciones para datos diploides de marcadores codominantes. En el análisis de los datos se calcularon las frecuencias génicas, genotípicas y se realizó un test de Hardy - Weinberg (Falconer y Mackay, 1996). Este test realiza la prueba de Chi - cuadrado $\left(\mathrm{X}^{2}\right)$ y la de Razón máxima verosimilitud $\left(\mathrm{G}^{2}\right)$ para cada locus de la población en estudio. Asimismo, se estimaron la homocigosidad y heterocigosidad observada y esperada, respectivamente, así como la heterocigosidad de Nei.

\section{Resultados y discusión}

Se estimaron los parámetros genéticos de la población de bovinos para el locus DRB3.2, locus DRB31 y locus BM1815. $\mathrm{Se}$ analizaron las relaciones que podrían darse entre los tres loci y el grado de asociación con la resistencia a la garrapata Boophilus microplus (Tabla 1).

La evaluación de la variabilidad electroforética en el locus DRB3.2 mostró que los productos de la reacción de PCR correspondieron a alelos $\mathrm{A}, \mathrm{B}$ y $\mathrm{C}$, que variaron en tamaños, en un rango de 400 a $500 \mathrm{pb}$ (Figura 1), formando en total 6 clases de genotipos.

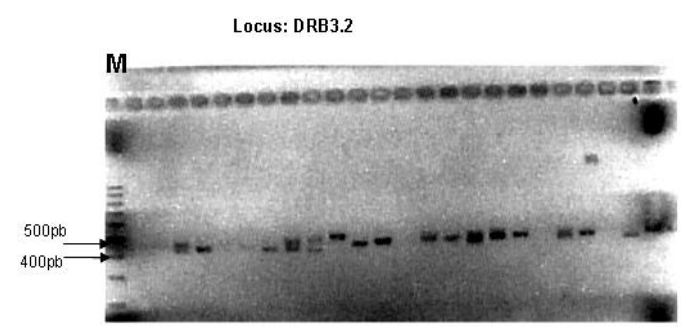

Figura 1. Resultados de la amplificación PCR de los alelos A, B y C del locus DRB3.2.

Las pruebas estadísticas para evaluar el nivel de equilibrio Hardy - Weinberg en este locus fueron las de Chi-cuadrado $\left(\mathrm{X}^{2}\right)$ y la de Razón máxima verosimilitud $\left(\mathrm{G}^{2}\right)$. En ambas pruebas se aprecia que para niveles de significación de $\alpha=0.05$ con 3 grados de libertad no hubo aceptación de que el locus se encuentre en equilibrio $\left(\mathrm{X}^{2}\right.$ $\left.=16.354 \mathrm{y} \mathrm{G}^{2}=16.0046\right)$. Asimismo, se nota que los valores observados de heterocigotos fueron menores que los valores esperados; mientras que los valores observados de homocigotos fue mucho más altos que los esperados. Estos resultados explicarían los niveles de consanguinidad que hay en la población y posiblemente un bajo grado de recombinación en este locus. 
Tabla 1

Relación entre la evaluación de bandas de tres loci del CMH BoLA clase II y el promedio de Boophilus microplus por bovino.

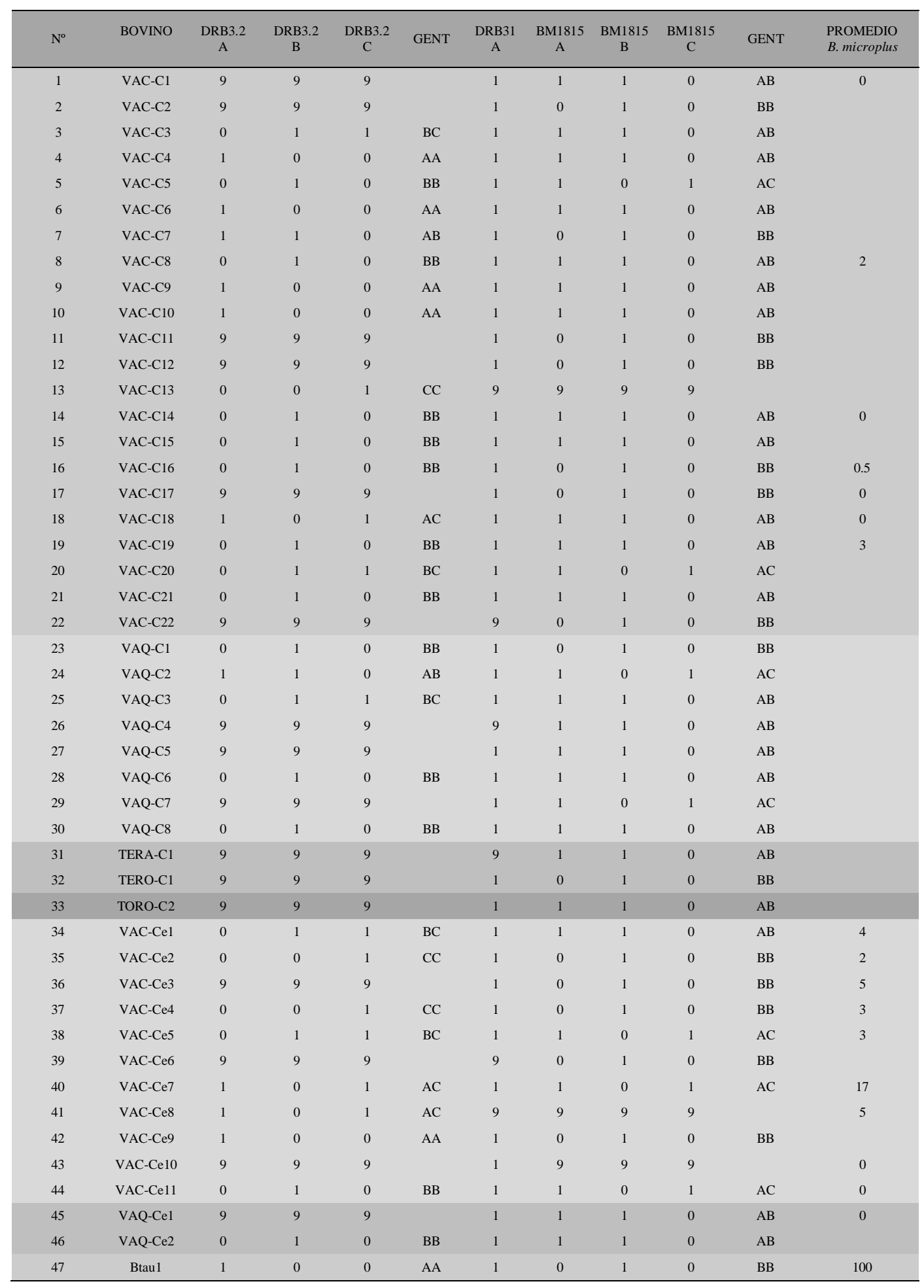


En locus DRB31 la evaluación electroforética mostró que los productos de la reacción de PCR correspondieron al alelo A con un tamaño de 300 pb, formando un solo tipo de genotipo (monomórfico para todos los individuos de la población de bovinos), lo que explicaría la escasa o nula recombinación genética en este locus, que se traduce en un descenso de la variabilidad genética; es decir caída de la eficacia biológica, derivada del fenómeno de depresión por consanguinidad que tiende a incrementar la presencia de homocigotos en la población y por ende el descenso de la resistencia a la garrapata B. microplus.

La evaluación de la variabilidad electroforética en el locus BM1815 mostró que los productos de la reacción de PCR correspondieron a alelos A, B y C, con tamaños alrededor de 200 pb (Figura 2), formando en total 6 combinaciones genotípicas. En este locus no se observa ningún homocigoto $\mathrm{AA}$ ni $\mathrm{CC}$ y tampoco heterocigotos CB. Sin embargo, la frecuencia de heterocigotos observados es mayor que los esperados. La prueba de equilibrio resultó más significativa que en el locus DRB3.2 (valores de $\mathrm{X}^{2}=$ $\left.19.685520 \mathrm{y} \mathrm{G}^{2}=25.391742\right)$.

El locus BM1815 a diferencia de los loci anteriores, está clasificado como una región microsatélite pequeña. Sin embargo, a pesar de su pequeño tamaño los resultados evidencian que este locus posee una mayor tasa de recombinación que los genes DRB3.2 y DRB31.

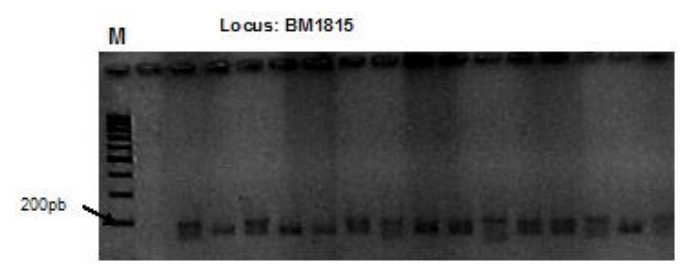

Figura 2. Resultados de la amplificación PCR de los alelos A, B y C del locus BM1815.
Las frecuencias alélicas de los tres loci del CMH BoLA Clase II en toda la población se grafican en la Figura 3, que ilustra la distribución de cada alelo de cada uno de los loci en la población total. Se puede observar que en el locus DRB3.2 el alelo más frecuente fue el alelo $\mathrm{B}$ con una frecuencia de 0.5000, mientras que los alelos A y $\mathrm{C}$ presentaron una frecuencia similar (Tabla 2).

El locus DRB31 fue monomórfico, y no se observaron en éste los alelos B y C. Sin embargo, en el locus BM1815 el alelo más frecuente correspondió al alelo B con una frecuencia de 0.5909 contrastando con la baja frecuencia del alelo $\mathrm{C}$ que presentó una frecuencia de 0.0795 .

\section{Tabla 2}

Frecuencias alélicas en tres loci del CMH BoLA Clase II de bovinos.

\begin{tabular}{cccc}
\hline $\begin{array}{c}\text { Alelo } \\
\text { Locus }\end{array}$ & DRB3.2 & DRB31 & BM1815 \\
\hline A & 0.2742 & 1.0000 & 0.3295 \\
B & 0.5000 & & 0.5909 \\
C & 0.2258 & & 0,0795 \\
\hline
\end{tabular}

La frecuencia del alelo $\mathrm{B}$ en el locus DRB3.2 indica que es ligeramente informativo, mientras que la frecuencia de este mismo alelo en el locus BM1815 indica que es un marcador muy informativo. Sin embargo, el alelo C mostró ser poco informativo para estos loci.

El polimorfismo que representa la frecuencia del alelo $B$ para el locus BM1815 concuerda con el polimorfismo reportado por Acosta et al. (2004), en el que evidenció la participación, al menos parcialmente, de varios alelos de Clase II del BoLA en la susceptibilidad a la infestación con garrapatas. 


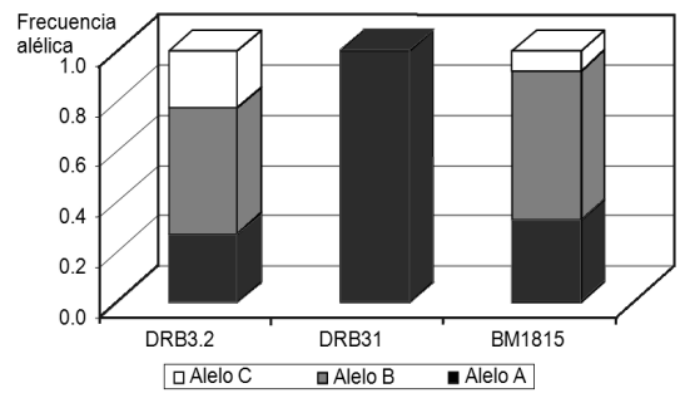

Figura 3. Distribución de frecuencias alélicas en tres loci del CMH BoLA Clase II.

Considerando que el polimorfismo por sí sólo no es una medida precisa de la variabilidad genética, debido a que un locus ligeramente polimórfico cuenta tanto como uno muy polimórfico (Falconer y Mackay, 1996), se ha estimado el nivel de heterocigosidad observada y esperada en función al equilibrio de Hardy-Weinberg a partir de las frecuencias alélicas de los tres loci en toda la población de bovinos, ya que es una buena medida de la variación porque estima la probabilidad de que dos alelos tomados al azar de la población sean diferentes.

En la Tabla 3 se muestra el resumen de la heterocigosidad donde se aprecia que la homocigosidad observada es mayor en el locus DRB3.2 y menor en BM1815.Mientras que la homocigosidad esperada fue ligeramente menor al obtenido en el locus BM1815.
En relación a la heterocigosidad, en el locus DRB3.2 la heterocigosidad observada reportó un menor valor que la heterocigosidad esperada, indicando una menor variabilidad en la población. En el locus BM1815 la heterocigosidad observada fue mayor a la heterocigosidad esperada. Además, la heterocigosidad de Nei resultó mayor a $50 \%$ en los loci DRB3.2 y BM1815. Y el promedio para los tres loci fue de $38.66 \%$.

La diferencia de heterocigosidad estimada entre los loci DRB3.2 y BM1815 corrobora que la muestra de la población está desviada, bien por efectos de consanguinidad o por el tamaño reducido de la muestra. Para corregir el sesgo producido se calculó la heterocigosidad esperada, dado que es un buen estimador de la variabilidad y se aplica a cualquier especie independientemente de su sistema reproductivo o estructura genética (Hedrick, 1999), siendo corroborada por la heterocigosidad de Nei (Tabla 3).

Por tanto, los resultados hallados permiten interiorizar el rol central que ocupa el Complejo Mayor de Histocompatibilidad (BoLA), en la respuesta inmune. Este complejo es de gran importancia para la adaptación del individuo al medio; por lo que influye directa e indirectamente sobre los caracteres de producción.

\section{Tabla 3}

Resumen de heterocigosidad y homocigosidad para tres loci en bovinos, Junín - Perú.

\begin{tabular}{lccccccc}
\hline Locus & $\mathrm{Na}$ & $\mathrm{HmO}$ & $\mathrm{HtO}$ & $\mathrm{HmE}$ & $\mathrm{HtE}$ & $\mathrm{HN}$ & $\begin{array}{c}\text { Promedio de } \\
\text { heterocigosidad }\end{array}$ \\
\hline DRB 3.2 & 62 & 0.6774 & 0.3226 & 0.3659 & 0.6341 & 0.6238 & 0.6083 \\
DRB 31 & 94 & 1.0000 & 0.0000 & 1.0000 & 0.0000 & 0.0000 & 0.0000 \\
BM1815 & 88 & 0.3409 & 0.6591 & 0.4579 & 0.5421 & 0.5359 & 0.5320 \\
Promedio & & 0.6728 & 0.3272 & 0.6080 & 0.3920 & 0.3866 & 0.3801 \\
DS & & 0.3296 & 0.3296 & 0.3426 & 0.3426 & 0.3377 & 0.3314 \\
\hline
\end{tabular}

$\mathrm{Na}$ : número de alelos totales, HmO: homocigosis observada, HtO: heterocigosis observada, HmE: homocigosis esperada, HtE: heterocigosis esperada, HN: heterocigosis de Nei, DS: desviación estándar. 


\section{Conclusiones}

Los alelos A, B y C de los loci DRB3.2 y BM1815 del Complejo Mayor de Histocompatibilidad BoLA Clase II están relacionados con la resistencia a $B$. microplus en ganado bovino y el alelo A del locus DRB31 está relacionado con la susceptibilidad. Las frecuencias de los alelos A, B y C, encargados de conferir resistencia a la garrapata B. microplus fueron:

- Locus DRB3.2: alelo A: 0.2742, alelo B: 0.5000 y Alelo C: 0.2258

- Locus BM1815: alelo A: 0.3295, alelo B: 0.5909 y alelo C: 0.0795 .

La frecuencia del alelo A en el locus DRB31 relacionado con la susceptibilidad a B. microplus fue de 1.0000 .

\section{Referencias}

Acosta, R.; Alonso, M.; García, V.; Flores, A.; Balladares, S.; Gorodezky, L.C. 2004. Participación del complejo principal de histocompatibilidad (MHC) de bovinos (BoLA) en la resistencia y susceptibilidad hacia la garrapata (Boophilus microplus). XXVIII Congreso de Buiatría. Asociación mexicana de médicos veterinarios especialistas en bovinos. México.

Álvarez, V.; Bonilla, R.; Chacón, I. 2003. Frecuencia relativa de Boophilus microplus (Acari: Ixodidae) en bovinos (Bos taurus y B. indicus) en ocho zonas ecológicas de Costa Rica. Rev. Biol. Trop. 51(2): 427 434.

Benavides, O.E.; Romero, N. 2001. Métodos y herramientas no convencionales, alternativas para el control sostenible de parásitos del ganado. Rev. Col. Cienc. Pec. Vol. 14.
Falconer, D.S.; Mackay, T.F.C. 1996. Introducción a la genética cuantitativa. $4^{\text {ta }}$ ed. Edit. Acribia, S. A. Zaragoza - España.

FAO. 2003. Resistencia a los antiparasitarios: Estado actual con énfasis en América Latina. P. 1 - 36.

Hedrick, P.W. 1999. Perspective Highly variable loci and their interpretation in evolution and conservation. Evolution. 53: 313 - 318 .

Hernández, A.H.; Mendiola, M.J.; Fernández, C.A.; Valdez, M. 2000. Identificación de una proteasa neutra en intestino de Boophilus microplus por electroforesis en geles de poliacrilamida copolimerizados con gelatina. Rev. Cubana Med. Trop. 52(3): 165 - 169.

Hess, M.; Goldammer, T.; Gelhaus, A.; Ried, K.; Rapold, G.; Eggen, A.; Bishop, M.D.; Schwerin, M.; Horstmann, R.D. 1999. Physical assignment of the bovine MHC class IIa and classIlb genes. Cytogent. Cell. Gentet. 85(3-4): 244 - 7.

Jonsson, N.; Mayer, D.; Green, P. 2000. Possible risk factors on Queesland dairy farms for acaricide resistance in cattle ticks (Boophilus microplus). Vet Parasitol. 88: 79-82

Mendiola, J.; Casanova, P.; Hernández, H.; Fernández, A.; García, I. 1997. Efecto de la digestión en la concentración de inmunoglobulina $\mathrm{G}$ en la ingesta de hembras de Boophilus microplus repletas. Rev. Cubana Med. Trop. 49(3).

Teale, A.J.; Kemp, S.J.; Morrison, W.I. 1994. The major histocompatibility complex and disease resistance in cattle. In: Owen AR, Gwynedd JB, editors. United Kingdom: CAB International. 86-99.

Villar, C.C. 2006. Los cruzamientos genéticos una alternativa para el control de la garrapata común del ganado Boophilus microplus en Sud América. Argentina. Disponible en: http://www.producciónanimal.com.ar

Yeh, F.C.; Yang, R.C.; Boyle, T.B.J.; Ye, Z.H.; Mao, J.X. 1997. Popgene version 1.32, the user friendly Shareware for population genetic analysis. Molecular Biology and Biotechnology Centre, University of Alberta, Canada. 